\title{
Training future language teachers to develop online tutors' competence through reflective analysis
}

\author{
NICOLAS GUICHON \\ Université de Lyon 2, Laboratoire ICAR, bâtiment FILTRE, 5, \\ avenue Pierre Mendès-France 69500 Bron, France \\ (email: nicolas.guichon@univ-lyon2.fr)
}

\begin{abstract}
This article sets out to identify key competencies which language tutors need to develop in order to manage synchronous online teaching. In order to aptly monitor interactions with distant learners, it is proposed that three types of regulation pertaining to socio-affective, pedagogical and multimedia aspects are required. On the one hand, this research aims at specifying these competencies and, on the other hand, it seeks to identify the relevance of reflective analysis for professional development.

The context of this study is a teacher training programme for Masters Degree students in teaching French as a foreign language that provides trainees with the opportunity of teaching online to intermediate-level students of French from a North American university via a desktop videoconferencing platform. This programme first endeavours to put trainees in a professional situation by getting them to prepare and administer sessions in order to confront them with the specific challenges of synchronous online tutoring. Second, it seeks to help them to gain insight into their own activity by developing critical thinking towards their own practice.

The data elicited for this research derive from the tutor trainees' interpretations of their own practice when confronted with the film of their own situated activity. The episodes chosen by the trainees to feed the self-confrontation process constitute significant units because by being told and commented upon, they elucidate how and to what extent competencies are built. Three discursive strategies have been identified and used to organise the content analysis of the data: description; expression of a difficulty; reflective review of the activity. The strategies used by trainees to verbalise their own activity can inform teacher educators about the constraints of the work situation and about the resources trainees need to deploy to face up to this unknown professional situation.

Results indicate that trainees concentrate particularly on pedagogical aspects that distance and faulty technology have rendered complex. The encountered difficulties are equally distributed between a repertoire of competencies pertaining to language teaching and competencies more directly linked with online teaching. Finally, this study has enabled us to assess the potential of self-confrontation for teacher practice and leads us to propose directions for improving this training device.
\end{abstract}

Keywords: Teacher education, desktop videoconferencing, critical analysis, competencies, selfconfrontation, synchronous computer-mediated communication 


\section{Introduction}

The advent of reliable videoconferencing facilities has resulted in the spread of synchronous computer-mediated communication (CMC) for social and professional use. In the field of e-learning, interactions among learners and instructors can now be accommodated (Clark, 2005) thus opening new teaching possibilities. More and more language schools now propose online language courses through desktop videoconferencing platforms and one can imagine that such technology-enhanced teaching practices that are both economical and potentially promising for language learning will become widespread in the years to come. This change will in turn require language instructors be trained to manage the specific challenges of synchronous online pedagogy.

The aim of the research described in this article is twofold. We first propose to define the key competencies that online teachers need to develop in order to adapt language pedagogy to a form of instruction that takes the affordances and constraints of distance and technology into consideration whilst enhancing the process of language learning. Because competencies develop in situated practice, this study will examine whether - and to what degree - the hypothesized competencies are deployed by online tutors in situation. The second aim is to verify the potential of critical analysis for the development of trainees' competencies so that trainers can determine ways to improve teacher education in the field of synchronous online language instruction.

The context of this study is a 45-hour course offered to Masters Degree students in teaching French as a foreign language, designed to train them to become online tutors. Dyads of trainees at a French university were asked to prepare pedagogical sessions and administer them through a desktop videoconferencing platform to dyads of intermediate-level French students at an American university for eight weeks. Each week, one of the pedagogical interactions between the trainees and the learners was filmed and then became the object of a debriefing session. Following the tenets of self-confrontation, a methodology devised by work psychologists (see 2.3) and used in teacher training (Linard \& Prax, 1984; Erben, 1999), the two trainees were then asked to select an extract from the filmed pedagogical interaction and analyze their own activity. This study will focus on these extracts and the interpretations given by trainees in order to study how they verbalize their practice and, in so doing, identify the difficulties they meet while confronted with this unknown pedagogical situation as well as the areas of professional development. In sum, this research mainly seeks to identify and describe emerging professional competencies and eventually feed the growing body of CALL research on online instructor training (Hampel, 2006; Jones \& Youngs, 2006; Lamy \& Hampel, 2007; Vetter, 2004).

\section{Theoretical rationale}

\subsection{What competencies for synchronous online language teaching?}

The emergence of Information Technology is undoubtedly accelerating the pace of change in terms of the competencies language teachers need to acquire and this has, 
in return, an impact on pre-service teacher education programmes. Two strategies with respect to introducing computer-assisted language learning (CALL) in teacher education can be identified. The first is that pre-service teachers can be exposed to the latest technologies during their pedagogical training and be provided with a set of technical skills they will be able to harness in their future professional environments. However, inherent in this strategy is a high risk that the technologies discovered during their initial training programmes might swiftly become obsolescent after they obtain certification (Hanson-Smith, 2006: 301). A more promising alternative consists in creating technology-enhanced learning situations whereby students acquire new professional skills through technology (Chapelle, 2003: 31).

Jonnaert and Vander Borght (2003: 53) propose a fruitful distinction between actual competency, which they define as "the capacity to successfully manage an unknown situation", and hypothetical competency, which corresponds to "the $a$ priori and decontextualized description of a set of skills a professional should have acquired at the end of her training". We suggest that the quality of teacher training lies in the opportunities it offers to transform pre-service teachers' hypothetical competencies into actual ones, so that they may feel ready to confront the reality of changing professional environments in which technology plays an ever-growing role.

The issue at stake when it comes to designing a curriculum for emergent professional roles, such as that of a synchronous online language teacher, is that researchers and teacher educators need to pinpoint their characteristics, compare them with similar roles (distant education, asynchronous online teaching) identified by research, and determine what competencies will be needed to perform these new roles once in situation.

Several authors, such as Bourdet (2006), Marchand \& Loisier (2005), and Jonassen et al. (2005), contend that distance in education provokes a fundamental change, leading instructors to adopt the role of a tutor instead of that of a teacher. Indeed, the main professional evolution identified by Bourdet (2006) concerns the fact that the relationship between instructor and learner shows greater equality when at a distance than in face-to-face teaching. Moreover, his research signals that distance and technology involve the development of new professional competencies in addition to those usually required for language teaching. In the same manner, in research studying the changes encountered by tutors at the Open University who had to adapt their pedagogy to a synchronous audio-graphic setting (Lyceum 3.6 (1999-2002)), Vetter (2004) notes that these instructors were led to perform new tasks linked to course planning and organisation and had to acquire new skills concerning communication, technical and socio-affective facets in order to perform their new roles efficiently.

Warschauer (2002) has identified four "electronic literacies" that comprise the ability to operate a computer (computer literacy), the ability to find and critically evaluate online information (information literacy), the ability to produce and interpret complex documents comprising texts, images, and sounds (multimedia literacy) and finally the ability to manage online interactions thanks to one's knowledge of the pragmatics of such interactions (computer-mediated communication literacy). The latter two types of literacy seem particularly relevant to synchronous online teaching.

Teaching competence, be it online or not, cannot be approached by establishing a set of appropriate behaviours or gestures that teachers need to adopt or perform. 
Rather, language teaching is an activity that requires a constant adjustment on a continuum between teacher regulation and learner complete autonomy. The notion of regulation stems from Piaget's (1975) work, which contended that regulation is a means of ensuring that a subject adapts in the process of interaction with his environment, the latter presenting both destabilising factors and potential resources. Regulation can intervene with the sole resources of the learner (self-regulation) or with the support of other peers or that of a teacher (other-regulation). Allal (2007: 8) suggests that regulation is comprised of several operations consisting of setting a goal and orienting one's action accordingly; monitoring the progress of the action toward its goal; and confirming or reorienting the trajectory of one's action. If the present research mainly focuses on other-regulation, that is to say on regulation provided by tutors, we share Allal's perspective that the learning progress eventually depends on the learner's self-regulatory process (2007: 11). This definition of regulation is in line with the sociocultural theory approach to second language learning which suggests that the teacher's utterances are "social practices that shape, construct, and influence learning within interactional and instructional contexts" (Donato, 2000). In this perspective, the main role of the teacher is to provide assistance, when needed, through scaffolding in the course of an interaction with the learners in order to help them develop their language skills. We thus posit that a teacher's main competence is a competence of regulation.

We define regulation as the set of actions and utterances deployed by a language teacher to create and maintain optimal conditions in a learning situation in order to provide opportunities to get learners to develop language skills. It is thus possible to hypothesize three main competencies specific to synchronous online tutoring, pertaining to (i) socio-affective regulation, (ii) pedagogical regulation and (iii) multimedia regulation and to describe them as follows:

(i) The competency of socio-affective regulation refers to the capacity to establish a relationship with a learner or a group of learners, to maintain it despite distance, and to eventually build a learning community. Several authors such as Marchand and Loisier (2005) have underlined the high rate of students dropping out from distance learning programmes because they necessitate a strong capacity for autonomous work coupled with a high level of motivation. Already important in face-to-face learning settings, socioaffective aspects become crucial when learning takes place at a distance (Carlson, 1997). Salmon (2000) has pinpointed several skills related to online communication that require that tutors display special attention to courtesy and respectfulness in online interactions, so as to overcome the psychological challenges posed by distance.

(ii) The competency of pedagogical regulation is at the heart of teaching, whether in face-to-face or in computer-mediated situations. It mainly consists of proposing clear and concise instructions, providing positive and negative feedback and deploying an array of strategies to facilitate second-language learning. It requires that teachers have an expert knowledge of the target language so as to provide timely assistance to facilitate the learners' language development. In the field of synchronous online tutoring, we suggest that the 
competency of pedagogical regulation concerns, first, the capacity to design learning scenarios adapted to distance that truly engage learners emotionally and cognitively and, second, to manage learning experiences by providing feedback tailored to learners' individual needs (Guichon \& Drissi, 2008).

(iii) Finally, the competency of multimedia regulation relates to the interfacing role of the online tutor who has to learn to use the communication tools (forums, blogs, videoconferencing facilities, etc.) that are the most appropriate to the learning scenarios, and to manage the ensuing interactions with the most adequate modalities (written, oral and/or video communication, synchronous and/or asynchronous). The competency of multimedia regulation encompasses both the "multimedia literacy" and the "computer-mediated communication literacy" as defined above by Warschauer (2002). This notion is very close to the "techno-semio-pragmatic" competency proposed by Peraya (2000), that is to say the capacity for an online teacher to achieve his purpose (language teaching) through the appropriate set of utterances, the adequate semiotic system and the best medium.

Our taxonomy does not include a category corresponding solely to technical competency because, in keeping with Chapelle's (2003) proposition, we posit that the technical dimensions of online tutoring permeate the socio-affective, pedagogical and multimedia competencies and cannot therefore be separated. Furthermore, these three types of competencies are hypothetical since they are constructs that are the result of past research. Our study aims to verify if those hypothetical competencies are actualised in the reality of synchronous online language tutoring.

\subsection{Confronting trainees with the urgency of synchronous online tutoring}

An aspect so far understudied in research on synchronous online teaching concerns the urgency that is specific to synchronous online tutoring. Admittedly, any kind of practice, be it professional or not, comprises an element of urgency because, unlike activities that are solely cognitive, practice is altered by time and its irreversibility. Teachers' expertise is thus characterized by their capacity to make timely decisions despite uncertainties in order to act swiftly and adequately. Indeed, class management often requires veering off a set course plan to answer an unexpected question, to face up to unusual learner behaviour, and to accelerate or slow down the pace of an activity to harness its full learning potential. Still, if urgency is inherent to any kind of practice, the temporal dimension of synchronous online tutoring is particularly salient. Indeed, synchronous online tutoring requires that the different participants are available at a given time. Attention has to be paid to differences in time zones, the simultaneous presence of the participants, appropriate and running equipment, and punctuality.

As it appears, synchronicity not only makes online teaching difficult to put into place but it renders communication delicate, as it can deteriorate unexpectedly and generate a great amount of anxiety (Develotte, Guichon \& Kern, 2008). The latter anxiety can be explained by the novelty of the situation, the temporal pressure exerted by synchronous communication and any technical failings of the videoconferencing platform 
(breakdowns, choppy video, discrepancy between sound and image). It is reasonable to think that the feeling of urgency and uncertainty experienced by these novice tutors might have an impact on the competencies of regulation defined above.

Confronting future language teachers with the urgency inherent to synchronous online tutoring can be highly formative because it incites them to perform a new role in a real situation according to the tenets of situated learning (cf. Egbert, 2006), so that they learn to "coordinate and sequence behaviour [and] to adapt dynamically to changing circumstances" (Clancey, 1995: 49). Because competencies are developed in situation, trainees should not only be exposed to the theories pertaining to online teaching, but should experience this form of teaching hands-on in a carefully devised programme. However, an equally important educational stake in developing the repertoire of these future professionals consists of getting them to realize that an activity deployed in the immediacy of practice is not the result of inspired improvisation. Rather, it stems from the modification of prior knowledge and habits when a specific situation is encountered. The capacity to command an unknown situation is what distinguishes novices from experts because the latter act in the tempo of that situation, are able to anticipate potential problems and to transform constraints into resources (Pastré, 2005: 236). Indeed, most expert teachers have acquired routines that allow them to face up to the unknown in the course of activity, whereas novices have not yet developed these competencies of other-regulation (management of learner activity) and self-regulation (management of one's own activity). The identification of the moments when a decision is made in the urgency of a situation therefore seems essential to teacher development because it involves learning to appreciate whether a given regulation is appropriate to a specific situation at a precise moment.

\subsection{Adopting reflective thinking to develop professional competencies}

The utilization of synchronous technologies by novice language teachers can hinder their apprenticeship by focusing their attention on technical aspects to the detriment of pedagogical ones. Moreover, the effect of heightened urgency intrinsically linked to synchronous communication can prevent them from gaining insight into their own activity. However, we posit that critical thinking towards one's contextembedded practice is a necessary condition to develop metacompetence. We define metacompetence as the conscious knowledge of and about teaching practice. In other words, it relates to the capacity to regulate one's own teaching activity so as to regulate learner activities. It may be developed by making the trainee aware of her behaviour in context and by getting her to think reflectively upon her activity. The metacompetence hypothesis stems from Bruner (1991: 69), for whom a narrative allows for the organisation of experience and the segmentation of events in order to facilitate the memorization of a particular process devised in a novel situation.

For Olson (1995: 121), such narratives provide "a kind of annotated template for future praxis in similar situations".

We suggest that metacompetence is what allows teacher trainees to:

- pin down competencies in construction and distinguish them from improvised behaviours; 
- articulate practice and instructional theory;

- identify areas of professional development;

- be able to transfer newly developed competencies to other professional situations.

To do so, trainees have to be encouraged to select episodes from a past sequence of activities and, by getting them to describe and comment upon these episodes, they should be led to become aware of their motives. The goal is to uncover the knowledge acquired in and on action (Schön, 1994; Theureau, 1992; Vermersch, 1994). It requires teacher educators to allow for opportunities in the programme in which the trainees' activity is desynchronized from their performance so as to fuel retrospective analysis.

It has become current practice in teacher education to use techniques that foster reflective thinking (Acheson \& Gall, 1987; Farrell, 2007; Stanley, 1998). Thus, Slaouti and Motteram (2006: 91) describe how they have set up an online community, thanks to such tools as forums and discussion groups, to favour reflection among teacher trainees and provide "a shared understanding about the roles of such tools in effecting deeper learning".

Self-confrontation, another technique much in use in France in teacher training (Linard \& Prax, 1984; Vermersch, 1994; Ciekanski, 2005) and in work psychology (Clot, 1999; Theureau, 1992), consists of confronting participants with the video recording of their own behaviour in a work situation and eliciting their comments in the presence of an expert or of their peers. The aim is to encourage them to describe and comment upon their activity, so as to lead them to focus their attention on the content of their actions, to make them explain their motives and to formulate a judgment both on the decisions made in the course of their activity and on the interpretations proposed during the debriefing session (Theureau, 1992: 45). The use of video recordings, rather than reconstructed memories of the trainees, contributes, on the one hand, to a deepening of their analysis of the activity based on manifest evidence, and, on the other hand, to creating a feeling of strangeness towards their own activity. By confronting the trainee with the image of her own activity, the aim is to encourage her to look at herself as she would look at someone else and incite her to find the words to make her activity intelligible to others. This is in line with the concept of "practical reason" devised by Ricœur (1986: 238) who contends that the significance of an action is dependent on its intelligibility, that is to say the extent to which it can be reported to oneself or to others and be accepted as intelligible.

Identifying episodes, describing and commenting on them for oneself and for others are thus the three stages of self-confrontation. This technique might be particularly adapted to attract the attention of trainees to critical incidents (Tripp, 1993; Hubbard \& Levy, 2006: 8) which correspond to moments in a professional situation when they face an obstacle and no ready-made process is available to surmount it efficiently. These critical incidents are particularly valuable for professional development because, by getting trainees to explain how they deal with the unknown, critical incidents reveal the elements that organise action and that were so far unidentified because they were hidden in the evidence of routine (Pastré, 2005: 77). We suggest that the episodes chosen by the trainees to feed their reflection - be they critical 


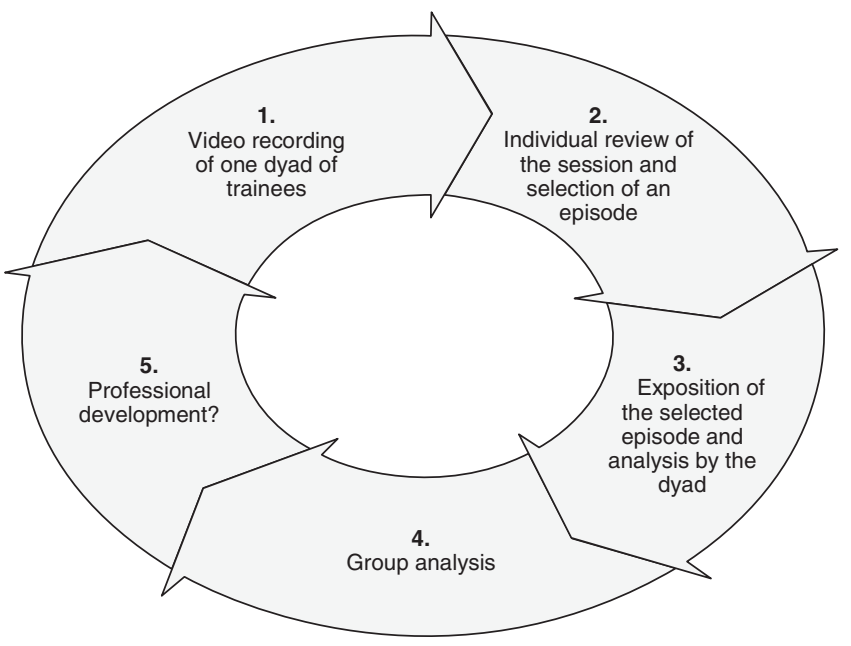

Fig. 1. Stages of the self-confrontation process.

incidents or not - constitute significant units because by being told and commented upon, they elucidate how and to what extent competencies are built. Further, the strategies used by trainees to verbalise their own activity can inform us about the constraints of the work situation and about the cognitive and emotional resources they need to deploy to face up to this unknown professional situation.

\section{Methodology}

\subsection{Presentation of the context of the research}

The training programme, in which this research was conducted, is a module available to Masters Degree students in teaching French as a foreign language at the University of Lyon 2. Sixteen students chose to follow this course which is entitled "teaching French at a distance". This group was made up of 14 women and 2 men, 10 French natives and 6 foreign students. None of them had significant teaching experience. Although this course within the training programme has been offered in other universities since $2002^{1}$, its novelty lies in the fact that it provides trainees with the opportunity of teaching online to intermediate-level students of French from a North American university via a desktop videoconferencing platform.

There are two stages in this programme. First, students were exposed to the theoretical underpinnings of distance language pedagogy and they also learned, for instance, to prepare tasks adapted to synchronous online teaching and to operate desktop videoconferencing facilities. Then, for eight consecutive weeks, trainees organised in dyads had to plan a teaching session that fit into the curriculum and the five-day-a-week French course followed by the Berkeley students. Figure 1 gives the detail of the stages of the self-confrontation process.

1 For more detail about the project, see "le français en $\left(1^{\text {ère }}\right)$ ligne": http://w3.u-grenoble3.fr/ fle-1-ligne 
For each of the weekly sessions, a dyad of trainees was in charge of analysing the requirements of the American curriculum (theme, teaching objectives), finding appropriate documents and activities and planning the session. The session plan was then presented to the other trainees, amended in the light of a group discussion and validated by the teacher on the Berkeley campus. The planned session was adopted by all the trainees and served as an outline for the pedagogical interaction with the Berkeley students which is conducted via a desktop conferencing platform. The stages shown in Figure 1 are further described as follows: (1) The dyad in charge of the session (DCS) is filmed during the interaction; (2) Right after the interaction, they are then asked to extract one episode they find significant so as to present it to the other members of the group and fuel the debriefing session; (3) In keeping with Linard and Prax's (1984) recommendations adopted by the educators, the DCS are the ones who choose the episode they show to the group; they have the command of the viewing tools and are the first to analyse their own activity; (4) Once the individual analysis is conducted, a group analysis takes place; the two teacher educators, one of whom is the author of this article, intervene mainly to recall the rules (respect of the others, need to propose constructive criticisms) when necessary, to stimulate the trainees' oral interventions, to feed the debriefing process, to orient it towards neglected aspects or to encourage active participation among all the trainees. It is thus noticeable that most of the training process is controlled by the trainees. The last stage of the process (5) is hypothetical because it concerns the areas of professional development that are permitted by this programme.

\subsection{Data collection and procedure}

Seven debriefing sessions out of eight (about seven hours) were filmed and transcribed $^{2}$ and the participants were identified for each conversational turn. The data thus comprise the seven debriefing sessions in their chronological order (from S1 to S8). To organise the data, only the first three initials of the participants' names have been kept, to protect their identity (e.g. VIN) and when the utterance was pronounced by one member of the dyad in charge of the session, it is signalled by DCS. For the purpose of this article, the trainees' quotes were translated from French to English and hesitations and speech meanders were kept so as to give the most accurate rendering of the verbalisation process.

We focused our study on the interventions of the DCS: first, we concentrated on all seven episodes that they had chosen to show to the rest of the group. A first analysis helped to identify how they presented the episodes, so as to define categories for the classification of the DCS's interventions. Three discursive strategies were identified:

(i) the simple description of an event (e.g. "it's been a lot of 'Can you hear me? Can you hear me? Is there any sound?');

2 Session 2 has been suppressed form the corpus because, due to technical failings, most of the pedagogical interaction took place through written chat and there were numerous breakdowns. The dyad was unable to extract one significant episode. 
(ii) the identification of a problem usually introduced by such expressions as "it was difficult ... I found it hard, I didn't know how..."; or

(iii) a reflection drawn from an event (e.g. "I try to keep speaking French as simply as possible, even if I have to recast, to repeat, because I think it's possible").

The second operation aimed to identify which of the three competencies of regulation (i.e. socio-affective, pedagogical or multimedia) in construction was the focus of the trainees' attention. One episode could be more or less rich (referring to several types of regulation). Thus, a single episode can contain several content units and these can be expressed in several manners (see appendix 1 for detail of the analysis).

The research questions we propose to address through this study are the following:

1. What is the nature of the selected extract? On what aspects do the trainees focus their attention?

2. What discursive strategies (description, expression of a difficulty, reflective review of the activity) are used by the trainees to organise the analysis of their activity?

3. To what extent does the self-confrontation process allow the teacher trainees to develop competencies and metacompetence?

\section{Results}

\subsection{The foci of attention}

The foci of attention, corresponding to the extracts selected by the dyad in charge of the session (DCS), were categorized according to whether they corresponded to critical incidents as defined in 2.3. Apart from two dyads who chose to show extracts that were gratifying (S1 and S4), most of the trainees selected episodes that fall in the category of critical incidents. Those relate to:

- the organisation of an activity complicated by distance (S3);

- the awkward management of a sequence of lexical explanation (S5);

- the difficulty in setting up a role play (S6);

- the faulty planning of an activity, which provoked learner incomprehension (S7);

- the management of a technical breakdown and the organisation within the dyad to face up to the problem (S8).

It seems that the trainees concentrate particularly on pedagogical aspects that distance and faulty technology have rendered complex.

Within the seven extracts, 44 content units were identified. Among the three types of regulation hypothesized in 2.1., global results indicate that half of the content units (21 out of 42) relate to pedagogical regulation; about one third (15 out of 42) deal with socio-affective regulation, while one in seven (6 out of 42) have to do with multimedia regulation.

It is worth underlining that most trainees are willing to take a risk by showing episodes that present them grappling with difficulties. Yet, all the dyads are not able to make the most of each episode, the number of content units varying from four to 
nine for each episode (see appendix 1). Some DCS prefer to escape the collective stare whereas others grasp this opportunity to explore their practice and reflect on their activity with the rest of the group.

\subsection{Three types of discursive strategy}

Among the three types of discursive strategies defined to qualify how the DCS present the episodes, 9 are descriptive, 13 relate to the expression of a difficulty and 22 concern critical reflection. The first two types mainly relate to the identification of an episode, whereas the third type pertains to the critical analysis of the activity. We will examine these three types in more detail and see what they reveal about the debriefing process.

4.2.1 Description. Descriptions constitute a way of dealing with the surface of the activity without any deeper exploration. Thus, in the following excerpt, one trainee (VIN, DCS, S3) explains how an information-gap task was organised and how it took place:

VIN: Well, first, uh, in spite of the exchanges with the [ American teacher in charge of the learners at UC Berkeley], we didn't know if [the worksheets] had been handed out... so, first, verify, ask "do you have them?", "yes", so they told us "yes, yes, we have the worksheet", etc., "have you read it?" "no", so, afterwards, so a first step, some assessment and some ... planning, and then, well, they immediately started to ask questions, and so afterwards we let them do that; well, my, how can I put it?, my own natural way, naturally, is to let them speak as much as possible, and then if ..., and if ... there are things to say, if there are still things to say, then to solicit them again."

This excerpt illustrates how this trainee undertakes a linear description (first, then, then, then) of his activity and mentions a series of action that seem logically linked (so). The enumeration of different actions seems to be the application of a set methodology as it appears through the use of various infinitives. The numerous hesitations and the attempts to find the right words (how can I put it?) indicate difficulty in getting into the detail of the activity and providing a more in-depth analysis. The proposition my own natural way, which concerns the degree of interference during learner oral production, shows that this participant does not question his role of tutor but presents it as self-evident.

4.2.2 The expression of a difficulty. More than half of the episodes chosen by the DCS are presented as problems encountered by the trainees. In these cases, the episode really takes on the value of a critical incident because the problem-solving process applies to an unknown situation.

Contrary to description, the expression of a difficulty indicates that the participants clearly identify a deficit of competency and no-ready made process is at their disposal to compensate for that deficit. Yet, the expression of a difficulty does not ensure critical thinking. Thus, the dyad in charge of session 7 mention four difficulties but this does not lead them to further analysis (see Appendix 1). 
Table 1 Types of difficulty encountered by trainees

\begin{tabular}{lc}
\hline \hline Problems linked with language teaching & Problems linked with online teaching \\
\hline \hline - Difficulty in explaining cultural & - Difficulty in managing one's own anxiety due \\
aspects & to technical failings \\
- Difficulty in designing activities adapted & - Difficulty in starting the dialogue with the \\
to the pedagogical objectives & learners because of distance \\
- Difficulty in organising an information & - Difficulty in assessing the learners' com- \\
gap activity with documents & prehension of an activity because of distance \\
- Difficulty in foreseeing the complexity & - Difficulty in managing several modalities \\
of each activity and determining & (written and oral) at once (mentioned \\
adapted objectives & 3 times) \\
- Difficulty in managing time & - Difficulty in managing time \\
\hline \hline
\end{tabular}

Table 1 presents all the difficulties encountered and verbalised by the DCS. They were organised into two categories, whether they pertain to problems linked with language teaching or with online teaching. Only time management falls in both categories. Dividing the data in these two categories should help determine what is specific to synchronous online tutoring and what falls in the overarching category of second-language teaching.

The difficulties encountered are equally distributed between a repertoire of competencies pertaining to language teaching and competencies more directly linked with online teaching. These results allow us to reassess the perceived impact of technology on trainees' preoccupations, and it is also a clear indication that core teaching competencies should not be neglected when it comes to prepare tutors for online teaching. However, the instability of the connection and aspects related to distance constitute important sources of problems which are often mentioned by the trainees. For instance, one trainee (ALI, DCS, S7) explains how distance complicates the start of a role-play between the learners:

"Anyway, for me, every time that we try role-plays, uh, like this, I don't know if it's the most... the most appropriate format. In fact, it's already complicated when you are a student to take on a role, and the fact they are at a distance ... and there's no preparation before, I mean, we ask them to be enthusiastic like this, out of the blue".

We can also notice that among the critical incidents presented by the trainees, the management of multimodal resources constitutes the main cause of difficulty as it is mentioned by three dyads out of seven. Devising emergency behaviours in case of technical failings, compensating for the effects of distance by careful communication and planning strategies, and using writing, speaking and the resources of webcamming in order to enrich pedagogical regulation, seem to represent three areas of teaching skills that are difficult for novice teachers to acquire.

4.2.3 Critical analysis. The last category for this study concerns discursive strategies in which the trainees dwell on episodes or critical incidents to draw a critical analysis of their own activity. For instance, the dyad in charge of session 5 explain 
Table 2 Problems solved or unsolved

\begin{tabular}{lc}
\hline \hline What is possible or necessary (12) & What remains problematic (10) \\
\hline \hline - Design tasks that involve & - What feedback should be provided to learners \\
learners & to improve their oral production? (4) \\
- Get familiar with the parameters & - How should the relationship be established \\
of the task before the session (2) & and maintained with the learners? (3) \\
- Adapt instructions and demands & - What can be done to start a task \\
to learners (2) & efficiently? \\
- Keep oneself in the background to & - How should grammar and vocabulary be \\
leave the floor to the learners (2) & taken into account in the learning process? \\
- Slow down the pace of speech so as & - What organisation could be chosen to make \\
to be understood & the tutor's activity more efficient? \\
- Express clear instructions and make & \\
sure they are understood & \\
- Make sure the learners participate evenly & \\
when they have a different level (2) & \\
- Adapt the modalities (written and/or & \\
oral message) to the demands of the task & \\
\hline \hline
\end{tabular}

why they reduced the use of the written modality so as not to dissipate their students' attention and to render the interaction with them more fluid:

JUL: there, we didn't use writing at all, or almost never, whereas we usually try to write one thing or two.

ELE: no, we didn't, but it's a choice we've made [...] not to write too much because we've realised that when we pelt them with messages, ... with written messages ... they don't pay attention to what we tell them, they are not able to go on with the activity, to ... All their attention goes to what's being written and everything stops.

This excerpt illustrates how some kind of expertise is being built thanks to experience, and how it impacts upon pedagogical and communication decisions (it's a choice we've made). The linguistic analysis of the different discursive strategies allows for the classification of their comments in Table 2 according to whether the problem on which they focus is solved (indicated by the use of modals such as can, could, need or should) or remains unsolved. The number of occurrences is indicated between brackets.

Table 2 indicates that the critical analysis of their activity allows trainees to either draw lessons (13 out of 23) or to acknowledge that some aspects of online teaching remain problematic (10 out of 23 ). The items in both columns delineate a repertoire of professional competencies that online tutors should develop and the issues they need to address to carry out their task efficiently. The recommendations listed in the left column have a particular status because they are grounded in a situated experience and could correspond to acquired competencies that can be mobilized in future online pedagogical interactions.

As regards unsolved problems, we note that the providing of feedback as well as the appreciation of the comprehensibility and the acceptability of learner oral 
output constitute important sources of interrogation. The timely interruption of learner output, the best ways to propose corrections and the most appropriate types of feedback are three pedagogical questions that have provoked much debate among the trainees. Similarly, socio-affective aspects related to the relationship with distant learners have raised many questions. Even if no precise answers were given to these questions in the course of the training programme, it is reasonable to think that the identification of these aspects - crucial for any language instructor - have heightened trainees' awareness and have prompted them to develop competencies in these areas.

The breakdown of trainees' critical comments along the eight weeks of training indicates that the capacity to question one's practice and to draw lessons from the analysis does not develop in a linear fashion but might also depend on the internal variables (participants' age, former experience, metacognitive skills, command of French) and external variables (class atmosphere, length of the training programme, didactic contract, phenomena of leadership). Not all trainees are able to go beyond a simple description or the expression of a difficulty to capitalise on their experience or their peers' experience.

It seems that only some dyads (DCS 3,4 and 5) were able to look critically at their own practice, while others remained at the surface of the activity or shied away from their own and their peers' scrutiny. Also, the uneven participation within each dyad should be underscored: if some trainees were very active, others confined themselves to an ancillary role of spectator, watching but seldom commenting upon their peers' activity. The chosen methodology, looking at the dyads' analysis and not at that of each individual within the dyads, does not allow us to go further in the individual development of metacompetence. This certainly indicates one of the limitations of this study.

\section{Discussion}

By confronting trainees with a real situation of synchronous online pedagogy, teacher educators incite trainees to learn to prepare lesson plans that allow for potential interpretations and adjustments so that the online exchanges are built interactively with the learners in real time. Because this situation is comprised of unknown and unexpected elements that cannot be ironed out by teacher educators, it presents an authentic potential to develop professional competencies in context. Also, the choice of forming dyads instead of having trainees deal with this new situation on their own, as will be the case in professional contexts, has enabled them to take turns and cooperate to solve the many problems they encountered in this novel teaching situation.

In the light of this study, several conclusions can be drawn about the relevance of self-confrontation for online teacher training. Self-confrontation produces a magnifying effect on crucial aspects of online teaching and draws trainees' attention to them. Further, our analysis has allowed us to verify that the three competencies required for synchronous online teaching (socio-affective, pedagogical and multimedia regulation), that we hypothesized in our theoretical framework, appear to be operative. This provides a framework for the organisation of online teacher training 
Table 3 Questions for assessing the quality of regulation

\begin{tabular}{ll}
\hline \hline Socio-affective regulation & - Has the relationship established with the learners been \\
& favourable to learning? \\
& - Have learners been sufficiently encouraged to take the floor? \\
& - Has feedback been individualised to learner needs? \\
Pedagogical regulation & Have the pedagogical objectives been fulfilled? \\
& - Have the documents and the tasks been conducive to support \\
& learning? \\
- Has the feedback provided during the session favoured \\
language learning? \\
Multimedia regulation $\quad$ Have communication tools been utilised efficiently? \\
- Has the choice of modalities efficiently supported the \\
interaction?
\end{tabular}

programmes and draws teacher educators' attention to certain aspects that need to be addressed more precisely. The study of the debriefing sessions has allowed us to formulate a certain number of questions (see Table 3) that could constitute criteria for trainees' self-assessment at the end of an online synchronous session.

Our study also revealed that there were few references to the technical aspects in the trainees' comments. This is no doubt due to the Instant Messaging programme ( $M S N$ messenger) to which a majority of them were already attuned for the purpose of social communication. Getting familiar with the communication tools should, however, not be neglected in a training programme especially if, instead of a familiar one, tutors utilize a platform specifically designed for distant learning as was the case with Lyceum 3.6 (1999-2002) at the Open University.

Our study can reasonably lead us to think that the identification of critical incidents during the debriefing sessions, their description and their critical analysis, first individually and then collectively, foster the creation of a community of practice that favours professional development (Hanson-Smith, 2006: 302).

This study has also allowed us to identify important differences between trainees as regards metacompetence. Indeed, certain participants remain at the surface of their activity and have difficulty in looking critically at their own practice in order to identify areas of development. This regulation of one's own competency not only depends on the didactic contract negotiated between the educators and the trainees but also on each individual's ability to look at her activity with sincerity and modesty and a willingness to extract the meaning of her practice. Developing reflective thinking demands cognitive (developing awareness of one's activity), psychological (agreeing to show something that is not flattering) and linguistic resources (finding the proper words to describe and comment). The discursive strategies identified in the analysis of the data are all related to the development of one's competence as a teacher but indicate different degrees in teacher development. If some are only able to identify and describe an episode, others are already able to set out the problem (the identification of a difficulty being the first step in problem resolution), and some of these are able to take up a critical stance toward their own practice and determine ways of improving it. 
If this ability to adopt reflective thinking towards one's own activity cannot be really developed in such a short period of time as eight weeks (Hampel \& Stickler, 2005: 323), one can hope that self-confrontation may sensitize trainees to the utility of critical thinking and may become part of their professional repertoire. Further, we had proposed (see 2.3) that metacompetence should encourage trainees to articulate practice and instructional theory, but the analysis of the data leads us to recognize that reference to instructional theory or even to other courses proposed in the degree are virtually absent from the trainees' comments, which signals a difficulty in linking theory and practice. It may also underline the fact that between language and activity, there is a permanent discrepancy which requires the constant adjustment of activity and its conceptualisation.

\section{Conclusion}

The emergence of new technological facilities, such as desktop videoconferencing, and the pedagogical and professional outcomes that they generate oblige CALL researchers to constantly refine their theoretical framework. This article has focussed in particular on previous studies on teaching (whether face-to-face, at a distance or asynchronously) and on research and methodology in work psychology, to determine the competencies that are required for a new type of language teaching that is somewhat modified by distance, technology and multimodality.

The identification and categorisation of these competencies were carried out through a linguistic study of the discursive strategies of trainees, when confronted with the task of analyzing their own activity in an online tutoring situation. This study results in the actualised identification of three main types of competencies pertaining to synchronous online teaching, relating to socio-affective, pedagogical and multimedia regulation. It also provides certain criteria for assessing the development of these competencies and, by way of a research-driven iterative process, for improving the training programme. It thus contributes to defining the contours of a form of teaching that is still in the early stages of development (Jones \& Youngs, 2006: 279).

Training programmes, such as the one put in place between teacher trainees in Lyons and Berkeley learners, confront pre-service teachers with new facets of their practice and should enhance their ability to implement CALL in the classroom (Joffe, 2000). It might also help them build professional competencies that are specific to online teaching. We believe that by creating opportunities for identification, verbalisation and interpretation, self-confrontation allows participants to extricate themselves from immediacy and from the technological environment inherent in synchronous online teaching, to develop metacompetence that might be reinvested in other contexts, and to regulate their own activity and act efficiently in the identification and the resolution of professional.

\section{Acknowledgement}

The study is part of ITHACA, a research programme funded by the French Agence Nationale de la Recherche. 


\section{References}

Acheson, K. A. and Gall, M. D. (1987) Techniques in the clinical supervision of teachers. New York: Longman.

Allal, L. (2007) Régulation des apprentissages: orientation conceptuelle pour la recherche et la pratique en éducation. In: Allal, L. and Mottier Lopez, L. (eds.), Régulation des apprentissages en situation scolaire et en formation. Bruxelles: De Boeck, 7-23.

Bourdet, J.-F. (2006) Construction d'un espace virtuel et rôles du tuteur. In: Dejean-Thircuir, C. and Mangenot, F. (eds.), Les échanges en ligne dans apprentissage et la formation. CLE International, 32-43.

Bruner, J. S. (1991) Car la culture donne forme à l'esprit. Paris: Georg Eshel.

Carlson, R. (1997) Educating online: Creating the virtual classroom community. ERIC ED 412 934.

Chapelle, C. A. (2003) English Language Learning and Technology. Amsterdam: John Benjamins.

Ciekanski, M. (2005) L'accompagnement à l'autoformation en langue étrangère: Contribution à l'analyse des pratiques professionnelles. Université Nancy 2. Unpublished doctoral dissertation.

Clancey, W. J. (1995) A tutorial on situated learning. In: Self, J. (ed.), Proceedings of the International Conference on computers and Education (Taiwan). Charlottesville, VA: AACE, 49-70.

Clark, R. C. (2005) Multimedia learning in E-courses. In: Mayer, R. E. (ed.), The Cambridge handbook of multimedia learning. Cambridge: CUP, 589-616.

Clot, Y. (1999) La fonction psychologique du travail. Paris: PUF.

Develotte, C., Guichon, N. and Kern, R. (in press) Allo Berkeley? Ici Lyon... Vous nous voyez bien? Etude d'un dispositif de formation en ligne synchrone franco-américain à travers les discours de ses usagers. Alsic, 11(2): 129-156.

Donato, R. (2000) Sociocultural contributions to understanding the foreign and second language classroom. In: Lantolf, J. P. (ed.), Sociocultural theory and Second Language Learning. Oxford: OUP.

Egbert, J. (2006) Learning in context. In: Hubbard, P. and Levy, M. (eds.), Teacher education in CALL. Amsterdam: John Benjamins, 167-181.

Erben, T. (1999) Constructing learning in a virtual immersion bath: LOTE teacher education through audiographics. In: Debski, R. and Levy, M. (eds.), WORLDCALL: Global perspectives on computer-assisted language learning. Lisse: Swets and Zeitlinger, 229-248.

Farrell, T. S. C. (2007) Reflective language teaching. London: Continuum.

Guichon, N. and Drissi, S. (in press) Tutorat de langue par visioconférence: comment former aux régulations pédagogiques? Les cahiers de l'ACEDLE, 5(1): 185-217.

Hampel, R. (2006) Rethinking task design for the digital age: A framework for language teaching and learning in a synchronous online environment. ReCALL, 18(1): 105-121.

Hampel, R. and Stickler, U. (2005) New skills for new classrooms: training tutors to teach languages online. Computer Assisted Language Learning, 18(4): 311-326.

Hanson-Smith, E. (2006) Communities of practice for pre- and in-service teacher education. In: Hubbard, P. and Levy, M. (eds.), Teacher education in CALL. Amsterdam: John Benjamins, 301-315.

Hubbard, P. and Levy, M. (eds.) (2006) Teacher education in CALL. Amsterdam: John Benjamins.

Joffe, L. (2000) Getting connected: Online learning for the EFL professional. ERIC document number 447298. 
Jonassen, D. H., Lee, C. B., Yang, C.-C. and Laffey, J. (2005) The collaboration principle in multimedia learning. In: Mayer, R. E. (ed.), The Cambridge handbook of multimedia learning. Cambridge: CUP, 247-270.

Jones, C. M. and Youngs, B. L. (2006) Teacher preparation for online language instruction. In: Hubbard, P. and Levy, M. (eds.), Teacher education in CALL. Amsterdam: John Benjamins, 267-280.

Jonnaert, P. and Vander Borght, C. (2003) Créer des conditions d'apprentissage, un cadre de référence socioconstructiviste pour une formation didactique des enseignants. Bruxelles: De Boeck.

Lamy, M.-N. and Hampel, R. (2007) Online Communication in Language Learning and Teaching. Palgrave Macmillan.

Linard, M. and Prax, I. (1984) Images vidéo, images de soi... ou Narcisse au travail. Paris: Dunod.

Lyceum 3.6 (1999-2002). The Open University, UK. System development: Samuel Marshall, Matthew Brown. Project management: Barbara Everatt.

Marchand, L. and Loisier, J. (2005) Pratiques d'apprentissage en ligne. Montréal: Les éditions de la Chenelière.

Olson, M. R. (1995) Conceptualizing narrative authority: Implications for teacher education. Teaching and teacher education, 11: 119-135.

Pastré, P. (2005) Genèse et identité. In: Rabardel, P. and Pastré, P. (eds.), Modèles du sujet pour la conception. Dialectiques activités et développement. Toulouse: Octarès, 231-260.

Peraya, D. (2000) Le cyberespace : un dispositif de communication et de formation médiatisées. In: Alava S. (ed.), Cyberespaces et formations ouvertes. Bruxelles: De Boeck Université, $17-42$.

Piaget, J. (1975) L'équilibration des structures cognitives: problème central du développement. Paris: PUF.

Ricœur, P. (1986) Du texte à l'action. Paris: Le Seuil.

Salmon, G. (2000) E-moderating: the key to teaching and learning online. London: Kogan Page.

Schön, D. A. (1994) Le praticien réflexif. À la recherche du savoir caché dans l'agir professionnel. Montréal: Les Editions Logiques.

Slaouti, D. and Motteram, G. (2006) Reconstructing practice. Language teacher education and ICT. In: Hubbard, P. and Levy, M. (eds.), Teacher education in CALL. Amsterdam: John Benjamins, 81-97.

Stanley, C. (1998) A framework for teacher reflectivity. TESOL quarterly, 32: 584-591.

Theureau, J. (1992) Le cours d'action: analyse sémio-logique. Berne: Peter Lang.

Tripp, D. (1993) Critical incidents in teaching: developing professional judgement. London: Routledge.

Vermersch, P. (1994) L'entretien d'explicitation en formation initiale et continue. Paris: ESF.

Vetter, A. (2004) Les spécificités du tutorat à distance à l'Open University: enseigner les langues avec Lyceum. Alsic, 7: 107-129.

Warschauer, M. (2002) A developmental perspective on technology in language education. TESOL quarterly, 36(3): 453-475. 
Appendix 1: Global results of the research

Sessions \& DCS Content units identified in the DCS' discursive strategies

S1 (5)

S3 (9)

S4 (6)

S5 (9)

C

S Description of the way the relationship is established with the learners

$\mathrm{P} \quad$ Difficulty in getting the learners to produce long and complex utterances

Difficulty in establishing fluid conversation

Reflection on the interest of providing linguistic correction

C Description of the management of modalities (written and oral) and the organisation within the dyad

S Difficulty in coping with anxiety because of technical incidents

Description of the socio-affective relation in construction

Reflection on the interest of careful course planning

P Reflection on the necessity to keep in the background to leave the floor to learners

Reflection on the necessity to slow down the pace of speech so as to be understood

Reflection on how to recast learners' inaccurate utterances

Description of a situation requiring improvisation

Difficulty in explaining cultural elements

Reflection on the need to individualize activities according to each learner's needs

C Description of the management of modalities within the dyad

$\mathrm{S}$ Reflection on how to establish the relation with the learners

Reflection on the need to make learners participate evenly when they have a different level

P Reflection on the time needed to start an activity because of distance

Reflection on the need to design tasks that involve learners

Reflection on the need to get familiar with the parameters of the task before the session

Difficulty in designing tasks that are adapted to pedagogical objectives

$\mathrm{S}$ Description of a misunderstanding between tutors and learners

Reflection on the necessity to keep in the background to leave the floor to learners

Reflection on the need to make learners participate evenly when they have different levels

Reflection on the way the relationship is established with the learners

Description of the organisation within the dyad

P Reflection on the comprehensibility of learner output

Reflection on the need to adapt instructions and demands to each learner's needs

Reflection on the learning process of grammar and vocabulary

C Reflection on the written modality and the need to reduce its place in the interaction

S6 (6)

S Difficulty in establishing an interaction between learners

Reflection on the importance of establishing a climate favourable to speaking L2

P Reflection on the importance of expressing clear instructions and making sure they are understood

Reflection on how and when to provide negative feedback 
Appendix 1: Continued

Sessions \& DCS Content units identified in the DCS' discursive strategies

C Difficulty in using the written modality while speaking

Description of how the written chat functionality is used to provide

S7 (4) feedback

S8 (4)

$\mathrm{S}$

P Difficulty in organising an information gap task with documents

Difficulty in assessing in advance the complexity of tasks and defining appropriate objectives

C Difficulty in assessing learner comprehension of the task

Difficulty in managing multimodality (oral vs written pace)

$\mathrm{S}$ Description of a lull in the interaction (a task cannot be started)

Reflection on tutoring alone rather than with a peer (organisation)

$\mathrm{P}$ Difficulty in managing time

C Difficulty in managing multimodality

Total amount of for different types of regulation $=44 \rightarrow$ socio-affective regulation $(\mathrm{S})=15$; pedagogical regulation $(\mathrm{P})=21$; multimedia regulation $(\mathrm{M})=8$

Description $=9$; Difficulty $=13 ;$ Reflection $=22$ 